\section{ACCURACY OF MACHINE} TOOLS

\section{PAVEL DOSTAL, MAREK SADILEK, JAROSLAV DUBSKY, PAVEL SZKANDERA}

Faculty of Mechanical Engineering, Department of machining, assembly and engineering metrology

VSB-TU Ostrava, Czech republic DOI: 10.17973/MMSJ.2020_03_2019132

Email: dostal.pa@email.cz

The accuracy of milling centre geometry is a basic condition for successful application in practice. Users of modern centres have to deal with the issue of measuring accuracy using in the production program. The desired results are achieved by careful preparation both before and during adjustment operations. These rules apply to all applications for new machines, but also to machines after collision or after handling older machines. The geometrical accuracy of the machine begins at the design stage, when the emphasis must be placed on the precision of production of parts and groups with the precise assembly of new machines. Even the best adjustment or alignment of the machine is not valid if the company orders a poor quality machine that does not meet the required characteristics both in design and quality. Such a poorly selected machine guarantees frequent interventions by technicians to ensure at least the minimum required tolerance.

KEYWORDS

machine-tool; measurement; accuracy; geometry; working accuracy

\section{INTRODUCTION}

When purchasing and positioning the machine, it is an important step to check the horizontal level using the vials. The machine must be placed horizontally and this horizontal must be maintained in all movements of the linear axes. These horizontal levels are achieved by precisely aligning the machine with anchoring elements in the lower bed, which are connected to the concrete foundation of the hall. If we have a high-quality precision machine that does not meet the precision requirements, it is important to look for problems from the ground up and focus on this anchor. After checking the horizontalness, it is necessary to check the flatness of the clamping surfaces of the machine table, the pallet and the perpendicularity of the milling spindle axis to these surfaces. The perpendicularity is also checked in the individual coordinate planes and a spindle runout test on the mandrel is performed [Janecki 2016]; [Stepien 2014]. All accuracy checks are performed on both 3 -axis and 5-axis machines, but for 5 -axis machines, these checks would not be complete. For these machines it is necessary to check the interaction of rotary and linear axes. The simplest task is to check the vertical axis with the rotation of the table, where the measuring pin and dial indicator find out the necessary information. More complicated control occurs at the tilting axes of the entire cradle, where we can no longer do without computer technology to determine the center positions. However, accuracy checks are more comprehensive and will be covered in the next chapters. [Vavrac 2010]; [Svoboda 2011]

\section{OVERVIEW OF THE CURRENT STATE OF THE ISSUES}

The accuracy of CNC machining centers is currently measured by various methods depending on the need to measure a particular component of the machine. During this preventive inspection, workers will focus on inspecting individual machine components, including motion guides, linear axis bolts, hydraulic and lubrication systems. For trouble-free operation of the machine, all support components such as covers, fans, position sensors and limit switches are cleaned during preventive checks. We also check the motors of the machine for axial movement or operation of peripheral devices. During preventive inspections we replace individual media and necessary filters. [Vavrac 2010]

The headstock inspection method is called vibration diagnostics. This method can reveal the condition of the bearings for the spindle bearing, the lubrication status and the total degree of vibration. Vibration diagnostics measures the spindle drives and can detect initial bearing damage. Milling and horizontal centers may have a problem with tool clamping by checking the clamping force. The results of this measurement are compared with the values of the manufacturer. The tapered spindle cavity can be checked with a color decal gauge. This test reveals, for example, point corrosion at the conical cavity. [Vavrac 2010]

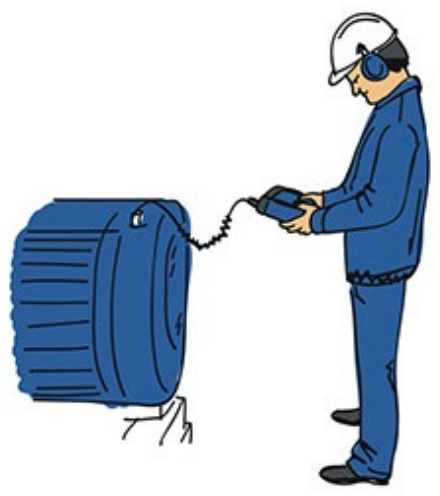

Figure 1. Vibration diagnostics [Adash 2019]

Circular interpolation control is a diagnostic method for CNC machine control using the Renishaw Balllbar measuring system, which diagnoses geometric accuracy and dynamic properties of drives. These tests can be performed in one plane, for example, in lathes or machining centers in multiple planes. The device senses deviations of measured values from the ideal circle. The resulting graph can be used to determine current machine errors that affect accuracy. Thanks to this check, it is possible to determine the origin of detected errors, whether they were caused by machine mechanics, incorrectly set drive dynamics or incorrect system metering. These discovered errors can be further investigated to determine which has the greatest impact on accuracy and suggest solutions for troubleshooting. Axial clearance can be corrected by entering compensation in the control system. [Vavrac 2010]; [Renishaw 2017]; [Rudawska 2016], [Smith 2015]

\section{CIRCULAR INTERPOLATION CHECK SYSTEM BALLBAR}

Renishaw's Ballbar QC20-W is designed for wireless measurement and control of machine tools. The Ballbar system consists of two parts, software and hardware. As a whole, it is able to measure geometric errors in CNC machines, their inaccuracies caused by servoregulation units or its own control system. The whole measuring system is set up using balls, which are stored in magnetic bowls. When the test is started, the machine will describe the circle or circular arcs and the radius deviations will be detected by the probe, which will then write them into the software. If the machine is perfectly adjusted without undesirable deviations, the data is displayed as a perfect circle. However, if the machine has deviations, it results in a deformation of the circle. 
Elliptical shapes or curvature may occur. [Renishaw 2017];[Smith 2015]; [Renishaw 2010];

The entire Ballbar measurement is sent by Bluetooth to the software, where total roundness, roundness variations and more are calculated. All data are processed according to ISO 230-4, ANSI / ASME B5.54 standards. The software evaluates the data into graphical and numerical form for better overview and diagnostics of the machine. The Telescopic Ballbar Linear Sensor is the most important component of the entire Renishaw assembly. The sensor has a diode that changes color depending on the status of the assembly. Green indicates the sensor is turned on without communicating with the system. The blue color represents the interconnection of the systems and if the LED flashes blue, data is transmitted. Slow blinking of green indicates power saving mode. Yellow indicates a low battery, flashing red and blue indicates a communication error, and a flashing red LED indicates a fault. The system uses volumetric diagnostics to calibrate the machine in the $X Y, Y Z$ and ZX planes. This diagnosis is shown in Figure 1 . The green circle represents the $360^{\circ}$ test in the $X Y$ plane with $45^{\circ}$ crossings, the blue line represents the $220^{\circ}$ test in the $Z Y$ plane with $2^{\circ}$ crossings, and the red line represents the $220^{\circ}$ test in the $\mathrm{YZ}$ plane with $2^{\circ}$ crossings. When testing the machine at regular intervals, it is possible to achieve the required accuracy, detect possible defects in a timely manner or reduce machine downtime depending on the reduction of the cost of scrap, eventually checking the machines. The measured data reveal the need for timely and correct machine maintenance. [Renishaw 2017];[Smith 2015]; [Renishaw 2010].

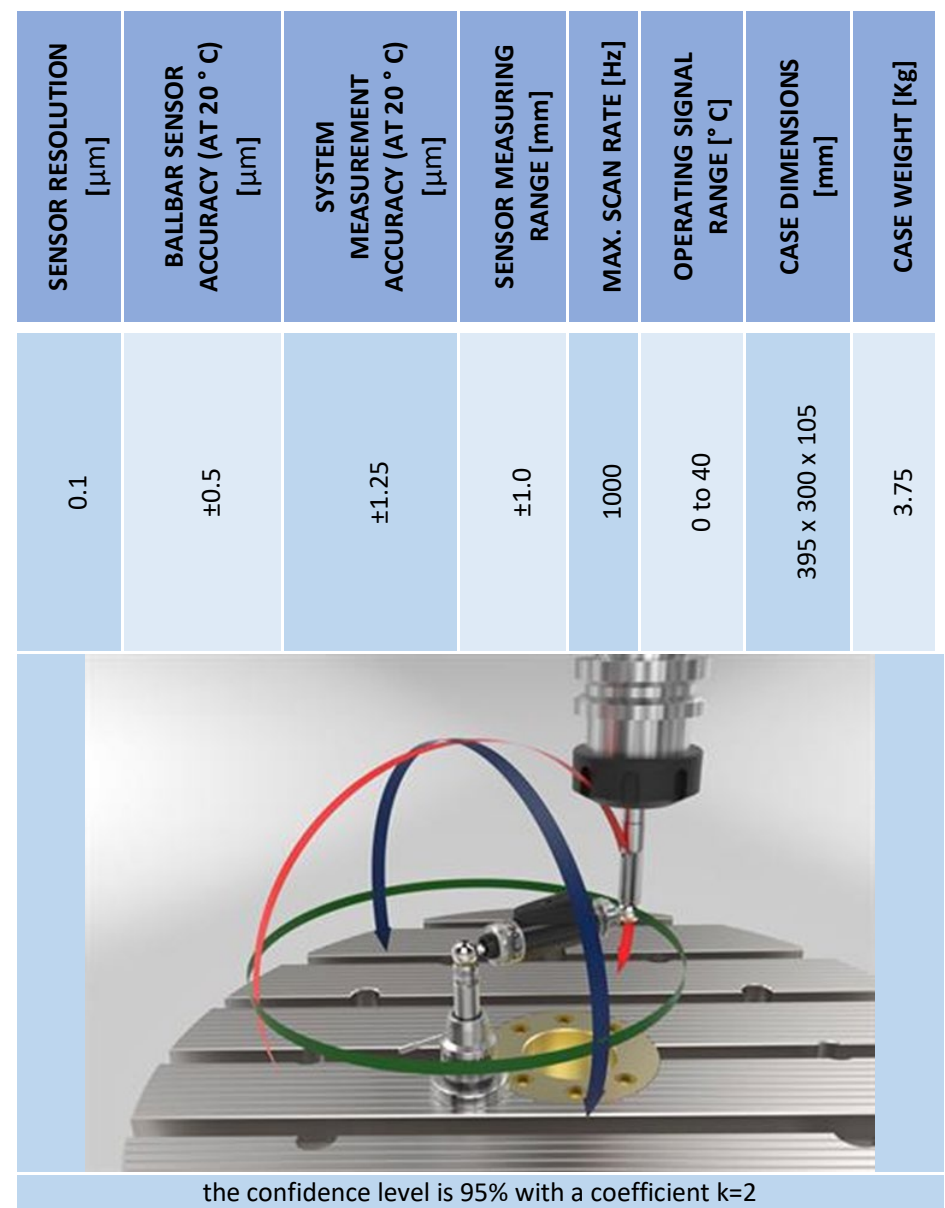

Table 1. Technical parameters of the Ballbar system
The measurement procedure for the different machines is the same, except that the set parameters in the software vary depending on the type of machine [Drbul 2016]. The procedure here is a description on the DMU 50. The measurement is performed on an unloaded machine. After switching on the machine is allowed to stabilize to the operating temperature, in the meantime the Ballbar measuring device is set. Machine data and measurement type are set in the system. The programs for the individual measuring planes are generated in the Ballbar software and transferred to the CNC milling software. It is important to clean the magnetic surfaces of the tool and center pan fixtures with a special cleaning compound to prevent dirt and metal particles from sticking to the measuring points. The cleaned components are clamped in the machine, the magnetic clamp in the machine spindle and the other on the workbench. The magnetic clamp is secured to the workbench by suitable clamps, the zero point setting and adjustment of the magnetic clamp relative position is done by the alignment ball. Before installing the telescopic linear encoder, a program check is performed for each measuring plane. If the CNC measuring programs show no error, the telescopic linear encoder can be switched on and paired with Renishaw Ballbar 20 on the PC. The calibrator verifies the calibration of the telescopic linear transducer, which must be done before each measurement. The measurement itself takes place in the following sequence. The machine spindle moves to the basic position for the start of the test, then a linear telescopic sensor is inserted between the magnetic clamps, the test is run in the measuring software and then the program in the CNC machine is started. The transfer and storage of the measured parameters into the measuring device software and all steps are repeated for the individual test planes. [Evans 2016]; [Yang 2002].

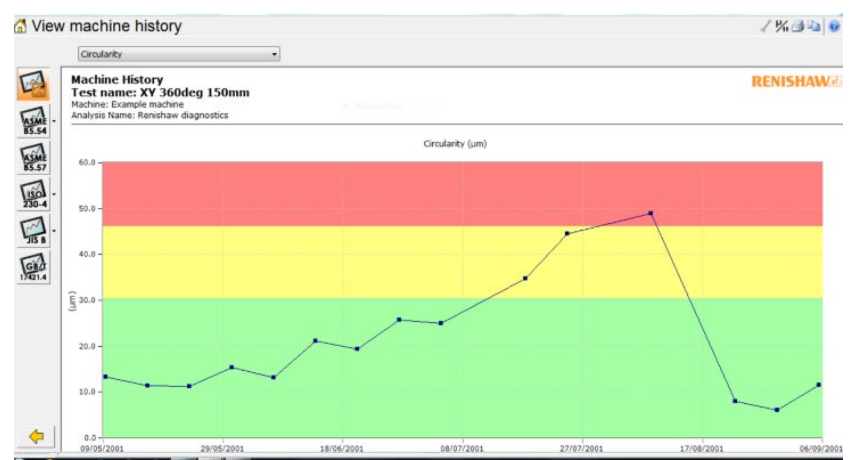

Figure 2. Graph of machine analysis over time

\section{MEASURED MACHINE AND CONTROL MEASURES}

For practical measurement was used machine DMU 50. DMU 50 is a CNC milling machine, which is located in the laboratory of Department of Machining, Assembly and Engineering Metrology dep.346, Faculty of Mechanical Engineering Technical University of Ostrava.

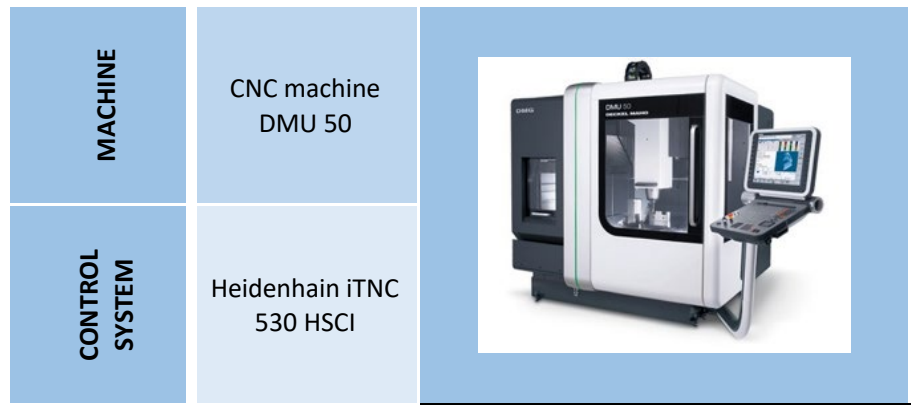




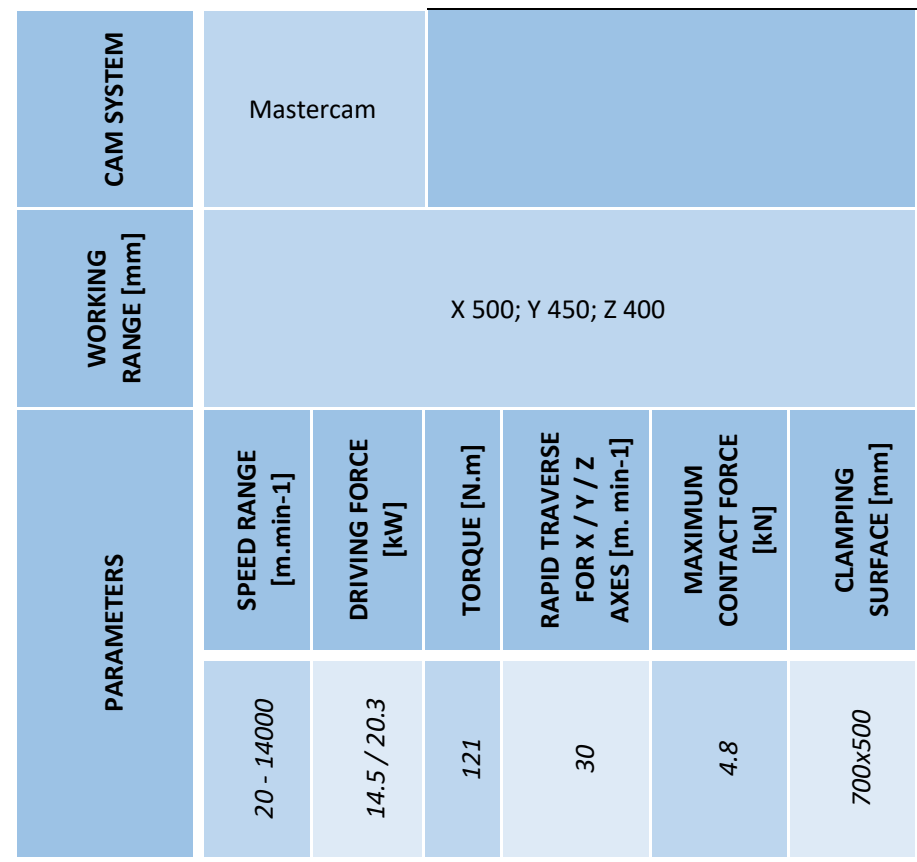

Table 2. Technical parameters of the DMU 50 [DMG Mori Europe 2019]

\section{SPINDLE ANALYSIS DMU 50}

Measurements are made to detect vibrations, generated deflection during spindle operation, causes high values and deflection. The condition of the bearings and the level of lubrication of the electric spindle bearings are also verified. Another measurement is to determine the state of the spindle face and the condition of the conical cavity by means of the runout of the mandrel. The state was assessed by multiparametric analysis at individual points.

A) In the band up to $1 \mathrm{kHz}$, the total value and the vibration velocity spectrum were measured in RMS detection with a comparison of standard values according to ČSN 200065. Measured in 3 axes.

B) Total value and vibration deflection spectrum up to 1 $\mathrm{kHz}$ in Peak-Peak detection for maximum spindle detection and comparison with limit values for a given type of machine tool according to ČSN 200065. Measurement performed in 3 axes.

C) Total value and vibration acceleration spectrum up to 15 $\mathrm{kHz}$ in Peak-Peak detection to determine total wear and level of bearing lubrication.

D) Total value and spectrum of vibration acceleration envelope up to $12.8 \mathrm{kHz}$ in Peak Detection to detect bearing condition. Used envelope filter $500 \mathrm{~Hz}-10 \mathrm{kHz}$ and $10 \mathrm{kHz}-40 \mathrm{kHz}$.

The MICROLOG GX frequency analyzer, piezoelectric accelerometer with an input sensitivity of $100 \mathrm{mV} / \mathrm{g}$, was used for measurement purposes. For unbalance, misalignment, mechanical clearance of the bearing and the like, the degree of freedom of the system 3 was used. [Jelinek 2018]

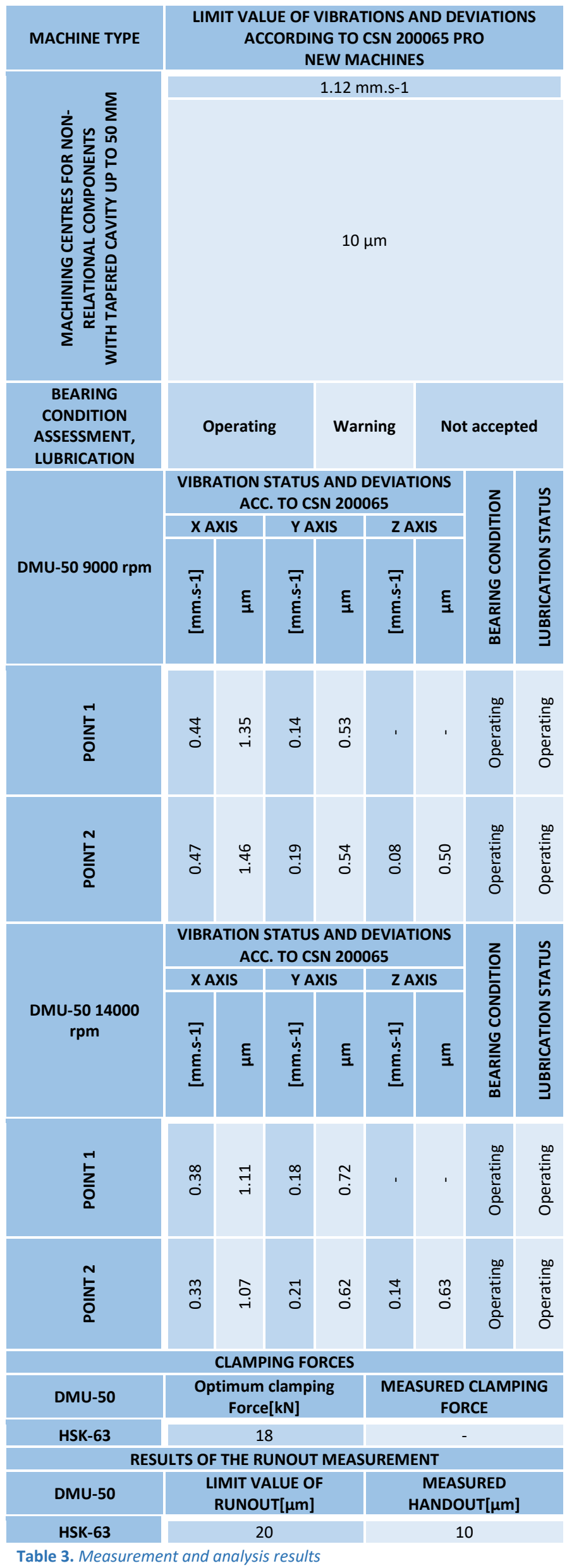


During the measurement the vibration rate was at a very low level and complied with the CSN 200065 standard, the spindle deflections in the $X$ axis are in the range of $1 \mu \mathrm{m}$, in other axes below the limit of $1 \mu \mathrm{m}$. Spindle imbalance is minimal, no loosening or play is detected. Stiffness is sufficient, but the running of the bearings has a deteriorated course, which does not jeopardize the running of the machine. The wear values are within the permissible limits, the tools and the spindle are not affected by heating. The runout is also satisfactory, the wear of the cone cavity and the spindle face is minimal. The machine can therefore be operated without restrictions with minimum vibration that could affect the production process.

\section{DETERMINATION OF REPEATABILITY AND POSITIONING COMPENSATION}

The positioning was determined and compensated according to CSN ISO 230-2 and CSN ISO 10791-4. The measurement was performed on an unloaded machine, a program was inserted into the machine so that the movements in the given axis were always in a number of specified positions. In these positions, the machine had to be long enough for its position to be recorded and accurately measured. The machine program has been programmed to move between positions at a specified speed or revolutions. Machine axes with a range of up to $2000 \mathrm{~mm}$ must have at least five positions per meter selected, all measurements being carried out in a standard cycle. Rotating surfaces are measured with a maximum measured angle of $45^{\circ}$. Each position is measured in both senses of movement, the change of meaning is created according to the normal movement of the machine. Renishaw laser interferometer was used for measurement. The instrument consists of a Renishaw XL-80 laser head, XC-80 compensation unit, Kombo Kit optics, LS 350 alignment optics, Renishaw XR-20 W rotary calibrator, and Laser 20 calibration software. All measured and compensated data are processed into graphs and tables. The position accuracy and repeatability measurements are recorded before the $\mathrm{X}, \mathrm{Y}, \mathrm{Z}, \mathrm{C}$ and $\mathrm{B}$ axes are adjusted and then measured after adjustment. The results meet the criteria of machine tools for precision finishing production according to CSN ISO 230-2 and CSN ISO 10791-4.

\section{ANALYSIS OF DMU 50 MACHINE}

The Ballbar measurement is performed as described in the chapters above, with the Ballbar probe calibrated using a calibration plate. The measurement spacing was set to $100 \mathrm{~mm}$. Only circular interpolation measurements for the $X Y$ plane are presented.

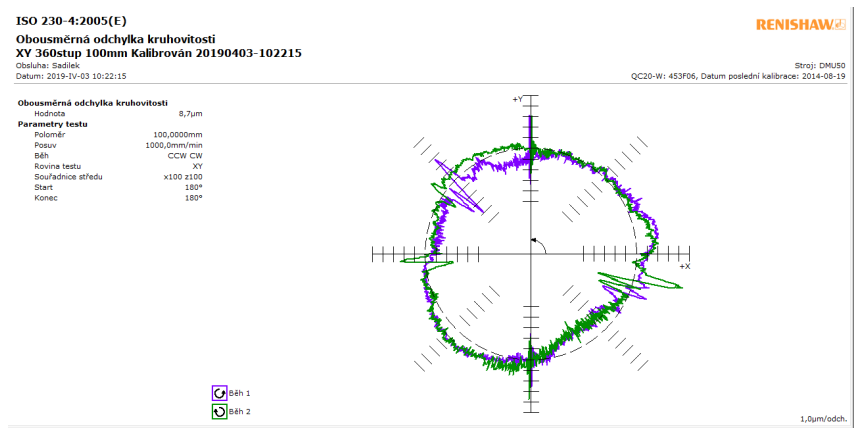

Figure 3. Roundness deviation in XY plane - first measurement

\begin{tabular}{|c|c|c|}
\hline \multicolumn{3}{|c|}{ BALLBAR DIAGNOSTICS $X Y 360^{\circ} \mathrm{R}=100 \mathrm{~mm}$ CALIBRATIONS } \\
\hline \multirow{3}{*}{ DEAD RUNNING $X$} & \multirow{2}{*}{ VALUE $[\mu \mathrm{m}]$} & $>0.1$ \\
\hline & & $<-0.2$ \\
\hline & INDEPENDENT CIRCULARITY $[\mu \mathrm{m}]$ & 0.2 \\
\hline \multirow{3}{*}{ DEAD RUNNING Y } & \multirow{2}{*}{ VALUE $[\mu \mathrm{m}]$} & $\Delta-0.3$ \\
\hline & & $\nabla 0.4$ \\
\hline & INDEPENDENT CIRCULARITY $[\mu \mathrm{m}]$ & 0.4 \\
\hline \multirow{3}{*}{ DELAY SERVOS $X$} & \multirow{2}{*}{ VALUE $[\mu \mathrm{m}]$} & $>0.0$ \\
\hline & & 41.5 \\
\hline & INDEPENDENT CIRCULARITY [ $\mu \mathrm{m}]$ & 1.5 \\
\hline \multirow{3}{*}{ DELAY SERVOS Y } & \multirow{2}{*}{ VALUE $[\mu \mathrm{m}]$} & $\Delta-2.6$ \\
\hline & & $\nabla-2.1$ \\
\hline & INDEPENDENT CIRCULARITY [ $\mu \mathrm{m}]$ & 2.6 \\
\hline \multirow{3}{*}{ TRANSVERSE CLEARANCE X } & \multirow{2}{*}{ VALUE $[\mu \mathrm{m}]$} & $>0.3$ \\
\hline & & 40.6 \\
\hline & INDEPENDENT CIRCULARITY [ $\mu \mathrm{m}]$ & 0.5 \\
\hline \multirow{3}{*}{ TRANSVERSE CLEARANCE Y } & \multirow{2}{*}{ VALUE $[\mu \mathrm{m}]$} & $\Delta-0.5$ \\
\hline & & $\nabla 0.4$ \\
\hline & INDEPENDENT CIRCULARITY [ $\mu \mathrm{m}]$ & 0.3 \\
\hline \multirow{3}{*}{ CYCLIC ERROR AMPLITUDE $X$} & \multirow{2}{*}{ VALUE $[\mu \mathrm{m}]$} & $\uparrow 0.2$ \\
\hline & & $\downarrow 1.1$ \\
\hline & INDEPENDENT CIRCULARITY [ $\mu \mathrm{m}]$ & 1.1 \\
\hline \multirow{3}{*}{ CYCLIC ERROR AMPLITUDE Y } & \multirow{2}{*}{ VALUE $[\mu \mathrm{m}]$} & $\uparrow 0.4$ \\
\hline & & $\downarrow 0.6$ \\
\hline & INDEPENDENT CIRCULARITY [ $\mu \mathrm{m}]$ & 0.6 \\
\hline \multirow{2}{*}{ SERVOS MISMATCH } & VALUE $[\mathrm{ms}]$ & 0.03 \\
\hline & INDEPENDENT CIRCULARITY [ $\mu \mathrm{m}]$ & 0.4 \\
\hline \multirow{2}{*}{ PERPENDICULAR } & VALUE $[\mu \mathrm{m} / \mathrm{m}]$ & -15.5 \\
\hline & INDEPENDENT CIRCULARITY [ $\mu \mathrm{m}]$ & 1.6 \\
\hline \multirow{2}{*}{ STRAIGHTFORWARDNESS $X$} & VALUE $[\mu \mathrm{m}]$ & 0.5 \\
\hline & INDEPENDENT CIRCULARITY [ $\mu \mathrm{m}]$ & 0.2 \\
\hline \multirow{2}{*}{ STRAIGHTFORWARDNESS Y } & VALUE $[\mu \mathrm{m}]$ & -2.9 \\
\hline & INDEPENDENT CIRCULARITY [ $\mu \mathrm{m}]$ & 1.5 \\
\hline \multirow{2}{*}{$\begin{array}{l}\text { RELATIVE ERROR } \\
\text { MEASUREMENT }\end{array}$} & VALUE $[\mu \mathrm{m}]$ & 1.0 \\
\hline & INDEPENDENT CIRCULARITY [ $\mu \mathrm{m}]$ & 0.5 \\
\hline $\begin{array}{l}\text { X-AXIS MEASUREMENT } \\
\text { ERROR }\end{array}$ & VALUE [ppm] & 21.3 \\
\hline $\begin{array}{l}\text { Y-AXIS MEASUREMENT } \\
\text { ERROR }\end{array}$ & VALUE [ppm] & 16.1 \\
\hline $\begin{array}{l}\text { WAVE LENGTH CYCLIC } \\
\text { ERRORS } \mathrm{X}\end{array}$ & VALUE $[\mathrm{mm}]$ & 3.175 \\
\hline $\begin{array}{l}\text { WAVE LENGTH CYCLIC } \\
\text { ERRORS Y }\end{array}$ & VALUE $[\mathrm{mm}]$ & 19.05 \\
\hline CALCULATED FEED & VALUE [mm.min-1] & 1011.7 \\
\hline CENTERING ERROR $\mathrm{X}$ & VALUE $[\mu \mathrm{m}]$ & -8.3 \\
\hline CENTERING ERROR Y & VALUE $[\mu \mathrm{m}]$ & 8.3 \\
\hline POSITION TOLERANCES & VALUE $[\mu \mathrm{m}]$ & 14.1 \\
\hline MEASURED RADIUS & VALUE $[\mathrm{mm}]$ & 100.0019 \\
\hline CIRCULARITY & VALUE $[\mu \mathrm{m}]$ & 8.7 \\
\hline
\end{tabular}

Table 4. Ballbar measurement results

\section{CONCLUSION}

The first measurements and analyses carried out using the Ballbar measuring instrument showed slight deviations in the machine accuracy, which were expressed both numerically and graphically. Accuracy measurement with subsequent correction will be performed for one year and the results will be processed in the report itself. After evaluating the results, the machine is calibrated, followed by a control sample, which is compared with the measured values. This output should assist in the calibration of machines using control samples and thus facilitate the acquisition of calibration data without the use of measuring instruments intended to measure machines.

The proposed control samples describe the shape of the circular interpolation path. Created models in CAD are used to create the 
program using CAM software. All data is compared with the actual state and measured using a measuring system. Circularity, cylindricality and other parameters will be determined using three coordinate instruments, optical measuring instruments and mechanical measuring machines. All measured data will verify the possibility of checking the accuracy of machine tools using control samples.

At a time when great emphasis is placed on the quality of production, it is not permissible to neglect the accuracy of the machines. Early detection of possible inaccuracies ensures considerable savings in machine repair. Detecting inaccuracies in front of its critical limit ensures planned and less costly machine maintenance. High reject rates are not permitted in any industry. Therefore, timely detection of any inaccuracies is of great benefit to production and maintenance.

\section{REFERENCES}

[Adash 2019] ADASH. Vibration diagnostics. [Online] 2019. [Quote: 5 November 2019.] https://adash.com/vibrationdiagnostics/vibration-diagnostics/.

[DMG Mori Europe 2019] DMG MORI EUROPE. DMU 50/70 series: CNC universal milling machines. DMG MORI. [Online] [Quote: 15 May 2019.] http://de.dmgmori.com/b lob / 123874 / 894e6b4926e63e3e9b64d4fd15f0005b / pm0uk15-dmu-50-70pdf-dat a.pdf.

[Drbul 2016] DRBUL, M., STANCEKOVA, D., BABIK, O., HOLUBJAK, J., GOROGOVA, I., VARGA, D.: Simulation possibilities of 3D measuring in progressive control of production. In: Manufacturing technology : journal for science, research and production, Vol. 16, no. 1 (2016), s. 53-58, ISSN 1213-2489.

[Evans 2016] EVANS, K. Circular Interpolation (G02 and G03). Industrial Press, 2016. ISBN 978-1-5231-3.

[Janecki 2016] JANECKI D., STĘPIEN K., ADAMCZAK S. Sphericity measurements by the radial method: I. Mathematical fundamentals, Measurement Science and Technology, Vol. 27, 1, 2016, pp. 0150051572-3.

[Jelinek 2018] JELINEK, M. Technical diagnostics analysis of spindle DMU 50. [Document] Ostrava: EMKOR Group s.r.o., 2018.

[Machalek 2018] MACHALEK, M. Determination of repeatability and positioning compensation according to CSN ISO 230-2 and CSN ISO 10791-4. [Document] Ostrava: EMKOR Group s.r.o., 2018.

[Stepien 2014] STĘPIEŃ K.: In situ measurement of cylindricityProblems and solutions, Precision Engineering, Vol. 38 No. 3 (2014), pp. 697-701

[Rudawska 2016] RUDAWSKA, A., RESZKA, M., WARDA, T., MITURSKA, I., SZABELSKI, J., STANCEKOVA, D., SKOCZYLAS, A.: Milling as a method of surface treatment in adhesive bonding. In: Journal of Adhesion Science and Technology, Vol. 30, iss. 23, (2016), s. 2619-2636, ISSN 0169-4243.

[Renishaw 2010] RENISHAW. QC20-W ballbar diagnostic system: description and specifications. [Online] 2010. [Quote: 5 May 2019.]

www.renishaw.cz/media/pdf/cs/fe351a817c58463cad0c9047cfe9 143c.pdf.
[Renishaw 2017] RENISHAW. Renishaw. QC20-W ballbar system. [Online] 2001-2017. [Quote: 5 May 2019.] www.renishaw.cz/cs/system-ballbar-qc20-w--11075.

[Smith 2015] SMITH, G. T. Machine tool metrology: an industrial handbook. New York : Springer Berlin Heidelberg, 2015. ISBN 9783-319-25107-3.

[Svoboda 2011] SVOBODA, O. Checking geometric accuracy of five-axis machines. Mmspektrum. [Online] 2011. [Quote: 5 May 2019.] https://www.mmspektrum.com/clanek/kontrolageometricke-presnosti-petiosych-stroju.html.

[Vavrac 2010] VAVRAC, J. Complex maintenance of CNC machine tools. Mmspektrum. [Online] 2010. [Quote: 5 May 2019.] www.mmspektrum.com/clanek/komplexni-udrzba-cncobrabecich-stroju.html.

[Yang 2002] YANG, Min-Yang and HONG, Won-Pyo. Threedimensional reference pulse linear and circular interpolators for CNC systems. [Document] Site Unknown: Business Source Ultimate, 2002. ISSN 0020-7543.

\section{CONTACTS:}

Ing. Pavel Dostal

doc. Ing. Marek Sadilek, Ph.D.

Ing. Jaroslav Dubsky

Ing. Pavel Szkandera

VSB-TU Ostrava

Faculty of Mechanical Engineering

Department of machining, assembly and engineering metrology dostal.pa@email.cz; www.vsb.cz marek.sadilek@vsb.cz; www.vsb.cz jardub@seznam.cz; www.vsb.cz pavel.szkandera@vsb.cz; www.vsb.cz 